\title{
Using A Mouthwash Containing Propolis, Clove Oil and Chlorhexidine to Improve the Caries Risk of High-risk Patients: Randomized Clinical Trial
}

\author{
Moataz Gamal Konsouh ${ }^{1 *}$, Mohammad Adel Ezzat Khairy² and Maha \\ Abdelsalam Elbaz ${ }^{3}$ \\ ${ }^{1}$ Master's Degree Student, Faculty of Dentistry, Cairo University, Egypt \\ ${ }^{2}$ Professor of Conservative Dentistry, Faculty of Dentistry, Cairo University, Egypt \\ ${ }^{3}$ Associate Professor of Conservative Dentistry, Faculty of Dentistry, Cairo University, \\ Egypt \\ *Corresponding Author: Moataz Gamal Konsouh, Master's Degree Student, \\ Faculty of Dentistry, Cairo University, Egypt.
}

\author{
Received: November 27, 2020 \\ Published: December 16, 2020 \\ (C) All rights are reserved by Moataz Gamal \\ Konsouh., et al.
}

\begin{abstract}
Aim: This study was conducted to determine the effect of using mouthwash of propolis, clove oil and chlorhexidine versus chlorhexidine mouthwash on the risk assessment of patients with high caries risk.

Materials and Methods: A total of 64 patients were assigned in this study. Patients were randomly divided into two groups according to type of mouthwash (A) where group A1 patients used Chlorhexidine mouthwash as control group while group A2 patients used Chlorhexidine with propolis and clove oil mouthwash as test group with 32 patients in each group. Each group was further divided into two groups according to application frequency (T) where T1 represents patients using the mouthwash once daily for one week every month for 6 months and T2 where patients used the mouthwash twice daily for one week every month for 6 months. Cariogram assessment was performed for each patient at baseline, 3 months and 6 months to obtain the caries risk percentage for each patient at the different time intervals.

Results: In the control group; significant decrease in the caries risk percentage resulted after 6 months (48.8 \pm 7.3 ) for the once daily application frequency. The same resulted for twice daily application frequency, significant decrease after 6 months (45.8 \pm 5.6 ). In the test group, significant decrease after 6 Months $(49.7 \pm 6.7)$ for the once daily application frequency. The same resulted for twice daily, significant decrease after 6 months $(46.3 \pm 6.0)$.

Conclusion: Within the limitations of this study, it can be concluded that:

- Adding propolis and clove oil to Chlorhexidine is not beneficial in caries prevention.

- The addition of propolis and clove oil to Chlorhexidine did not affect the reduction of bacterial $S$. mutans count in the oral cavity to a clinical significance.

- $\quad$ Adding propolis and clove oil did not prolong the antimicrobial effect of Chlorhexidine on S. mutans.

- $\quad$ Chlorhexidine mouthwash should be used twice daily to have a substantial effect in reducing oral $S$. mutans count.

Keywords: Dental Caries; Caries Risk Assessment; Mouthwash; Chlorhexidine; Propolis; Clove Oil; Streptococcus mutans; Bacterial Count
\end{abstract}




\section{Introduction}

Dental caries is the major cause of the hard-dental tissue disease in the human population. It's a dynamic multifactorial disease of the hard-dental tissue accounted to be the major cause around the world of teeth destruction and loss [1]. With the new understanding of the dental caries process new methods have been devised to prevent it, such as stopping the problem at the beginning by preventing plaque accumulation on teeth surfaces and prevention of growth of acid producing bacteria that cause demineralization of dental enamel surface. S. mutans (Streptococcus mutans) is one of the main pioneer bacteria of dental caries. Its virulence is determined by adherence, acidogenicity and acid tolerance. Preventing this bacteria from colonization and acid production is evidenced to prevent the process of dental caries and reduce individual's caries risk [2].

Caries risk assessment is an important part of modern dentistry because caries is prevalent and can be avoided as well as curable. It is therefore important to identify relevant factors early, which may increase the risk of caries. Dental caries is well known to be a multifactorial disease, the extent of which is affected by the general health, diet of the patient, the amount and type of bacteria present in the oral cavity, salivary factors, and fluoride exposure. In addition to traditional oral data, information on lifestyle, living conditions and general health is useful for determining the impact of risk factors for dental caries. Higher morbidity associated with chronic diseases, use of xerostomic side effects medications, frequent intake of carbohydrates, and severe dentition restoration are additional risk factors that challenge older people. In addition, frailty and the physical and mental deterioration associated with aging influence personal oral hygiene habits significantly [3-5].

Chlorhexidine is a well-tested compound and its plaque control properties are well documented. However, the prolonged usage of Chlorhexidine leads to its undesirable side effects such as teeth staining and altered taste sensation. Therefore, developing alternative agents with antimicrobial properties and minimal side effects or modifying Chlorhexidine products to potentiate or prolong their effect is a logical approach. Antimicrobial agents of natural origin have proven to be promising source in the development of new drugs and therapeutic products throughout human history. Recently, several studies have presented strong evidence on the feasibility of using medicinal plants as a source of antimicrobial agents for preventing oral diseases $[6,7]$.

Propolis is a natural antibiotic. The medicinal properties are due to the flavonoids, phenolics and various aromatic compounds. Flavonoids have antibacterial, antifungal, antiviral, antioxidant and anti-inflammatory proprieties. Galangin, pinocembrin and pinostrobin are known as the most effective flavonoids agents against bacteria. Ferulic acid and caffeic acid also contribute to the bactericidal action of propolis [8]. Propolis has a potent activity against Gram-positive, Gram-negative organisms and even against Candida [9]. Certain chemical components of propolis act on the cell wall of microorganisms causing functional and structural damages. It has muco-protective effect and so can be used efficiently in the oral cavity. Within the philosophy of health promotion, the extracts of propolis represent a new option showing long-term beneficial effects in caries prevention [10].

Clove (Syzygium aromaticum) is an herb that its essential oils are most widely used in food seasoning. The antimicrobial capacity was identified when many Gram-positive and Gram-negative species including certain fungi were killed by its essential oil extracts. The high levels of eugenol contained in clove essential oil are responsible for its strong biological and antimicrobial activities. It is well known that both eugenol and clove essential oil phenolic compounds can denature proteins and react with cell membrane phospholipids changing their permeability and inhibiting a great number of Gram-negative and Gram-positive bacteria as well as different types of yeast [11-13].

\section{Materials and Methods}

Materials

- Intervention: Chlorhexidine Gluconate $0.12 \%$ with Propolis 1\% and Clove Oil 1\% (Dg-Care Mouthwash, AlEsraa Pharmaceuticals, Egypt) 
- Comparator: Chlorhexidine HCL $0.12 \%$ mouthwash (Hexitol Mouthwash, The Arab Drug Company (ADCO), Egypt)

- $\quad$ CRT Buffer System (Ivoclar Vivadent Inc, US)

- Brain Heart Infusion Broth Medium (Oxoid Ltd. Wade Road Basingstoke, Hants, UK)

- $\quad$ Mitis-Salivarius Agar (HiMedia Laboratories Pvt.Ltd, LBS Marg, Mumbai -400086, India)

Methods

Study design and selection of sample

This four-armed, parallel-design, and randomized clinical trial study was conducted in the Clinic of Conservative Dentistry Department, Faculty of Dentistry, Cairo University, Egypt after the approval of the Ethics Committee in the Faculty of Dentistry - Cairo University. The researcher was responsible for all activities associated with the research including recruitment of participants, explaining and performing the procedures to them. The procedure and the aim of the study was explained to the participants and an informed consent was signed by each of them.

Study setting and participants:

A total of 64 patients were assigned in this study. Patients were randomly divided into two groups according to type of mouthwash (A) where group A1 patients used Chlorhexidine mouthwash as control group while group A2 patients used Chlorhexidine with propolis and clove oil mouthwash as test group with 32 patients in each group. Each group was further divided into two groups according to application frequency (T) where $\mathrm{T} 1$ represents patients using the mouthwash once daily for one week every month for 6 months and $\mathrm{T} 2$ where patients used the mouthwash twice daily for one week every month for 6 months [14].

\section{Eligibility criteria of participants}

Inclusion criteria

- Patients should be over 18 years of age

- $\quad$ Patients should be with high caries risk assessment.

\section{Exclusion criteria}

- $\quad$ Patients with a compromised medical history

- Severe or active periodontal disease

- $\quad$ Patients with a diseased salivary gland

- History of allergies or other adverse reactions to chlorhexidine, propolis, bee stings, or clove

- $\quad$ Patients on any antibiotics during the past month

- $\quad$ Patients undergoing radiotherapy

- $\quad$ Patients with prosthesis or orthodontic appliances [15].

\section{Sample size calculation}

Based on the paper by Netto., et al. (2013) [16] the expected difference in $S$. mutans count decrease from baseline between chlorhexidine with propolis and clove oil mouthwash versus chlorhexidine mouthwash was $0.3 \pm 0.5 \mathrm{CFU} / \mathrm{ml}$. By calculating the effect size $(\mathrm{d}=0.73)$ and transforming it to $(\mathrm{f}=0.4)$ to use 2-way ANOVA in analysis, using power $80 \%$ and $5 \%$ significance level, total sample size of 52 patients (13 in each group) would have been sufficient. This number was increased to 64 to compensate for possible losses during follow up (16 in each group). Sample size was calculated by G power program.

\section{Trial description}

\section{Recruitment strategy}

Screening of patients that came into the conservative dentistry department seeking dental care continued until the target population was achieved. The patients were then subjected to full examination and diagnosis using dental charts. Once the patients that potentially eligible for this study were identified, they were contacted by the research investigator who explained the study and ascertained the patient's interest. If the patient showed interest, more detailed evaluations and preparations were made. 


\section{Randomization and assignment of intervention}

Allocation sequence generation

Simple randomization was done according to a check list including the number of participants divided into 2 groups denoting with A1 and A2. Randomization was generated using the website (www. randomization.com).

\section{Allocation concealment mechanism}

Allocation of mouthwash and times of applications to groups was done through sealed opaque sequentially numbered containers and envelopes to ensure absolute concealment. All eligible participants who gave consent for participation were randomized into four groups. A participant dentist other than the researcher performed the allocation sequence and assigned the participants to mouthwash and times of administration in sequentially numbered sealed opaque containers

\section{Blinding}

The participants and the main operator were blinded to intervention/control assigned and the designated mouthwash was bottled in a sequentially numbered sealed opaque containers by another operator. Also, it was not allowed amongst the examiner, the participant dentist and trial subjects to exchange any information regarding the type of the assigned treatment throughout the entire study period.

\section{Caries risk assessment}

The caries risk assessment was done using the Cariogram model. The Cariogram is a computer program that evaluates data collected from the patient such as $S$. mutans count, DMFS (decayed, missing, or filled surfaces) or DMFT (decayed, missing, or filled teeth) score, diet contents, diet frequency, plaque amounts, fluoride program, salivary secretion rate, and saliva buffering capacity. When scores of 7 out of the 10 parameters are entered, the software starts to produce a pie diagram which represents the percentages of 'Diet' (Dark Blue), 'Bacteria' (Red), 'Susceptibility' (Light Blue), 'Circumstances' (Yellow). These 4 sectors dictate the percentage of 'Chance to avoid new caries' (Green) sector. Hence the bigger the green sector, the lesser is the risk of caries and vice versa. The bigger the green sector, it is considered better from dental health point of view. Small green sector means low chance of avoiding caries which indirectly means high caries risk hence the caries risk is calculated by (100-Chance to avoid new caries) $[17,18]$.

\section{Saliva sample}

The patient was instructed not to smoke, consume food or drink (except water), brush the teeth or use a mouth wash for at least one hour prior to the scheduled appointment time. As the trial period is for 6 months, standard dental care was provided to every patient after baseline caries risk assessment which included scaling, excavation and filling of carious lesions, extraction of hopeless teeth and remaining roots, and patient education on oral hygiene measures and instructions [2].

\section{Salivary flow}

The baseline saliva sample was obtained after the patient chewed for one minute on paraffin wax and spit in a sterile measuring cup for two minutes to measure the rate of flow of stimulated saliva then the secretion rate was calculated. Time could be decreased if salivary flow was high, increased if secretion was low. Collected stimulated saliva was used in other tests [14].

\section{Bacterial count}

A $1 \mathrm{ml}$ saliva sample for $S$. mutans counts test was collected in a sterile test tube containing $1 \mathrm{ml}$ of brain-heart infusion broth medium then stored in an icebox on dry ice $\left(-70^{\circ} \mathrm{C}\right)$ and transported immediately to microbiology department, Cairo University within 2 hours of collection. The samples were vortexed for 2 minutes to uniformly mix the saliva. Using a micropipette (calibrated from 10$100 \mu \mathrm{l}), 0.1 \mathrm{ml}$ of the vortexed sample was added to $1 \mathrm{ml}$ saline to make (1/10) dilution. Ten-fold dilution was repeated until a final 
Using A Mouthwash Containing Propolis, Clove Oil and Chlorhexidine to Improve the Caries Risk of High-risk Patients: Randomized Clinical Trial

dilution of 3 ten-fold was obtained. $50 \mu \mathrm{l}$ from each of the dilutions was taken by the micropipette and was spread by a sterile glass rod on the culturing plates containing mitis salivarius bacitracin agar selective for $S$. mutans for determining the count. The plates were incubated in a candle jar inside the incubator at $37^{\circ} \mathrm{C}$ for 48 hours. These $S$. mutans colonies on the plates were expressed as number of colony forming units per milliliter (CFU/ml x104) of saliva. microbial counts were performed by a single examiner, who was unaware of the treatment of the patients. These procedures were repeated at the three different time intervals of the study [19-22].

\section{Saliva Buffering Capacity:}

A quick and easy way to determine the saliva buffering capacity is using the CRT Buffer system. A drop of saliva is placed on the test pads and it dissolves the dried acids and pH sensitive dyes on the pads. This system can discriminate between low (yellow), medium (green) and high (blue) buffer capacity [23].

\section{Other data}

Other required data such as related general diseases, diet contents, diet frequency, and fluoride program were collected in the medical and dental history of the patient. Plaque index and DMFT score were collected during the intra-oral clinical examination of the patients. Plaque index was determined according to Silness and LöE, (1964) [24]. All data were scored according to a standardized protocol and then entered into the Cariogram program to provide the pie diagram. All the previous steps are repeated at 3-and 6-months visits. During the period of this trial patients received the standard dental care provided by the different departments of the Faculty of Dentistry Teaching Hospital in Cairo University. Patients were instructed to withhold the fact that they are participating in a trial from the treating operators as to insure they do not receive any special treatment $[14,25]$.

\section{Data collection methods}

Baseline data collection

Medical history, dental history and examination charts were filled by the operator in a chart for each participant.
Outcome data collection

$[17,18]$

\begin{tabular}{|c|c|c|}
\hline Factor & $\begin{array}{c}\text { Information to be } \\
\text { collected }\end{array}$ & Cariogram Score \\
\hline $\begin{array}{c}\text { Caries } \\
\text { experience }\end{array}$ & $\begin{array}{c}\text { DMFT, new caries } \\
\text { experience }\end{array}$ & $\begin{array}{l}\text { 0: No caries, no fillings } \\
\text { 1: Better than normal for the age } \\
\text { group } \\
\text { 2: Normal for the age group } \\
\text { 3: Worse than normal for the age } \\
\text { group }\end{array}$ \\
\hline $\begin{array}{l}\text { Related } \\
\text { general } \\
\text { diseases }\end{array}$ & $\begin{array}{l}\text { Medical history, } \\
\text { medications }\end{array}$ & $\begin{array}{l}\text { 0: Healthy } \\
\text { 1: Presence of a general disease } \\
\text { that can indirectly influence the } \\
\text { caries process } \\
\text { 2: Continuous medication or } \\
\text { bedridden }\end{array}$ \\
\hline Diet content & $\begin{array}{l}\text { Diet history: } \\
\text { quality of diet }\end{array}$ & $\begin{array}{l}\text { 0: Very low fermentable } \\
\text { carbohydrate } \\
\text { 1: Low fermentable carbohydrate } \\
\text { intake } \\
\text { 2: High fermentable carbohydrate } \\
\text { 3: Very high fermentable } \\
\text { carbohydrate }\end{array}$ \\
\hline $\begin{array}{l}\text { Diet } \\
\text { frequency }\end{array}$ & $\begin{array}{l}\text { Questionnaire re- } \\
\text { sults: quantity of } \\
\text { dietary intake }\end{array}$ & $\begin{array}{l}\text { 0: Maximum } 3 \text { meals/day } \\
\text { 1: Maximum } 5 \text { meals/day } \\
\text { 2: Maximum } 7 \text { meals/day } \\
\text { 3: More than } 7 \text { meals/day }\end{array}$ \\
\hline $\begin{array}{c}\text { Amount of } \\
\text { plaque }\end{array}$ & Plaque Index & $\begin{array}{c}0:<5 \% \text { plaque adhering surfaces } \\
1: 5 \%-20 \% \text { plaque adhering } \\
\text { surfaces } \\
2: 21 \%-50 \% \text { plaque adhering } \\
\text { surfaces } \\
\text { 3: }>50 \% \text { plaque adhering surfaces }\end{array}$ \\
\hline $\begin{array}{l}\text { Streptococ- } \\
\text { cus mutans }\end{array}$ & $\begin{array}{c}\text { Bacterial Count } \\
\text { Test }\end{array}$ & $\begin{array}{c}0:(0-4) \times 10^{4} \mathrm{CFU} / \mathrm{ml} \\
1:(5-29) \times 10^{4} \mathrm{CFU} / \mathrm{ml} \\
2:(30-199) \times 10^{4} \mathrm{CFU} / \mathrm{ml} \\
3: 200 \times 10^{4} \mathrm{CFU} / \mathrm{ml}\end{array}$ \\
\hline
\end{tabular}


Using A Mouthwash Containing Propolis, Clove Oil and Chlorhexidine to Improve the Caries Risk of High-risk Patients: Randomized Clinical Trial

\begin{tabular}{|c|c|c|}
\hline $\begin{array}{c}\text { Fluoride } \\
\text { program }\end{array}$ & $\begin{array}{c}\text { Fluoride expo- } \\
\text { sure }\end{array}$ & $\begin{array}{c}\text { 0: Maximum fluoride exposure } \\
\text { 1: Additional fluoride measures, } \\
\text { but infrequent applications } \\
\text { 2: Fluoride toothpaste only } \\
\text { 3: Avoidance of fluorides }\end{array}$ \\
\hline $\begin{array}{c}\text { Saliva } \\
\text { secretion } \\
\text { rate }\end{array}$ & $\begin{array}{c}\text { Secretion rate on } \\
\text { stimulated saliva } \\
\text { test }\end{array}$ & $\begin{array}{c}\text { 0: Normal saliva secretion } \\
\text { 1: Low, 0.9-1.1 } \mathrm{mL} / \mathrm{min}\end{array}$ \\
$\begin{array}{c}\text { 2: Low, } 0.5-0.9 \mathrm{~mL} / \mathrm{min} \\
\text { buffering } \\
\text { capacity }\end{array}$ & $\begin{array}{c}\text { Dentobuff or } \\
\text { digital pH meter }\end{array}$ & $\begin{array}{c}\text { 0: Adequate, saliva } \mathrm{pH}>6.0 \\
\text { 1: Reduced, saliva } \mathrm{pH} 4.5-5.5 \\
\text { 2: Low, saliva } \mathrm{pH}<4.0\end{array}$ \\
\hline $\begin{array}{c}\text { Clinical } \\
\text { judgement }\end{array}$ & $\begin{array}{c}\text { The examiner's } \\
\text { own clinical and } \\
\text { personal score } \\
\text { for the individual } \\
\text { patient }\end{array}$ & $\begin{array}{c}\text { 0: More positive } \\
\text { 1: Normal setting } \\
\text { 2: Worse }\end{array}$ \\
& 3: Very high caries risk \\
\hline
\end{tabular}

Table 1

\section{Adherence}

Thorough and complete contact information was obtained from each patient with emergency contacts and each patient was reminded of the follow up appointment 24 hours prior to it. Since the intervention was done entirely by the patient, adherence monitoring was a must. Measuring of the amount of the mouthwash remaining in each visit gave an indication on the level of adherence. Periodic phone calls, phone messages, and WhatsApp group messages between visits encouraged the patients and increased adherence, it also helped in detecting non-adherence by self-reporting or from the patient's family.

\section{Statistical methods}

Data presented with mean and standard deviation when appropriate. Data explored for normality using Kolmogorov-Smirnov test. Caries Risk Percentage and CFU/ml showed a parametric distribution. Repeated measures ANOVA used to evaluate the effect of different tested mouthwashes and application frequency on mean Caries Risk Percentage and CFU/ml. Multiple comparison followed the former test with Bonferroni correction. Significant level was set at $0.05(\alpha=0.05)$. Statistical analysis was done using Statistical Package for the Social Sciences (IBM SPSS Statistics for Windows, Version 23.0. Armonk, NY: IBM Corp.

\section{Results}

\section{Caries Risk Percentage:}

For each of the 64 participants in this study, caries risk assessment was obtained at each time interval. Patients were allocated into 4 groups according to mouthwash provided and application frequency.

\section{Comparison between different tested mouthwashes}

Table 2 showed the mean and standard deviation (SD) for Caries Risk Percentage for the different tested groups where in the once daily application frequency, the control group (CHX only) had mean percentage $(87.8 \pm 4.3)$ and the test group (CHX+Propolis+Clove) had mean percentage $(88.7 \pm 4.1)$ at baseline and there wasn't significant difference between them $(p=0.538)$. After 3 months the mean percentage for the control group was $(50.8 \pm 5.8)$ and the test group was $(50.8 \pm 5.5)$ with no significant difference between them $(p=1.00)$. After 6 months there wasn't significant difference as the mean percentage for the control group was $(48.8 \pm 7.3)$ and the test group $(49.7 \pm 6.7)(p=0.70)$. As for the twice daily application frequency it showed that the control group had a mean percentage $(90.3 \pm 2.3)$ which was significantly higher compared to the mean percentage of the test group $(87.3 \pm 4.9)$ at base line $(p=0.042)$. After 3 months it showed insignificant difference between control $(47.7 \pm 6.8)$ and test $(46.3 \pm 6.0)$ groups ( $p=0.503)$, and also after 6 months there was insignificant difference between control (45.8 $\pm 5.6)$ and test $(46.3 \pm 6.0)$ groups $(p=0.827)$.

Figure 1 is a bar chart showing the mean Caries Risk Percentage for different tested mouthwashes where in the once daily application frequency group there was insignificant difference between control and test groups at base line, after 3 months, and after 6 months. As for the twice daily application frequency it shows that control group demonstrated higher risk values compared to the test group at base line but after 3 and 6 months there is insignificant differences between control and test groups.

Comparison between different tested mouthwashes application frequency

Table 3 showed mean and standard deviation for Caries Risk Percentage for different tested mouthwashes application frequen- 
Using A Mouthwash Containing Propolis, Clove Oil and Chlorhexidine to Improve the Caries Risk of High-risk Patients: Randomized Clinical Trial

\begin{tabular}{|c|c|c|c|c|c|c|}
\hline \multirow{2}{*}{ Caries Risk Percentage } & \multicolumn{2}{|c|}{ Control } & \multicolumn{2}{c|}{ Test } & \multirow{2}{*}{ p-value } \\
\cline { 2 - 7 } & & Mean & SD & Mean & SD & 0.538 NS \\
\hline \multirow{2}{*}{ Once Daily } & Baseline & 87.8 & 4.3 & 88.7 & 4.1 & $1.00 \mathrm{NS}$ \\
\cline { 2 - 7 } & $3 \mathrm{~m}$ & 50.8 & 5.8 & 50.8 & 5.5 & $0.702 \mathrm{NS}$ \\
\cline { 2 - 7 } & $6 \mathrm{~m}$ & 48.8 & 7.3 & 49.7 & 6.7 & $0.042^{*}$ \\
\hline \multirow{2}{*}{ Twice Daily } & Baseline & 90.3 & 2.3 & 87.3 & 4.9 & $0.503 \mathrm{NS}$ \\
\cline { 2 - 7 } & $3 \mathrm{~m}$ & 47.7 & 6.8 & 46.3 & 6.0 & $0.827 \mathrm{NS}$ \\
\cline { 2 - 7 }
\end{tabular}

Table 2: Mean and standard deviation (SD) for Caries Risk Percentage for different tested groups.

*: Significant; NS: Non-significant.

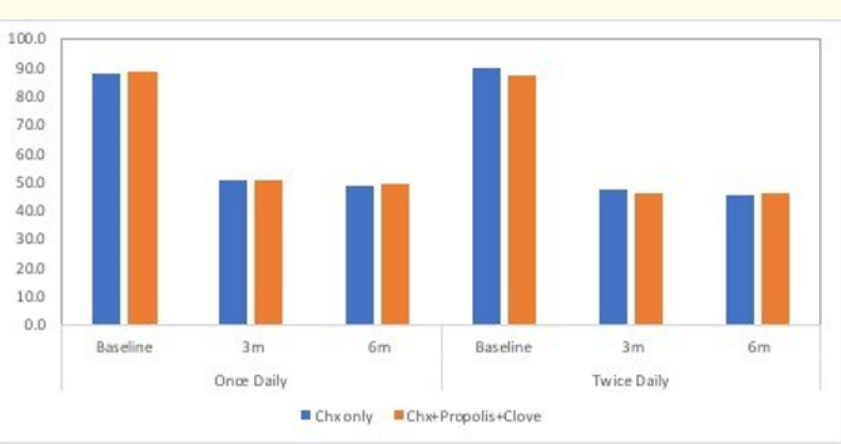

Figure 1: Bar chart for mean Caries Risk Percentage for different tested mouthwashes. cies where the control group (CHX only) showed insignificant difference between once daily $(87.8 \pm 4.3)$ and twice daily $(90.3 \pm$ $2.3)$ application frequencies at base line $(p=0.09)$. After 3 months there was insignificant difference between once daily (50.8 \pm 5.8 ) and twice daily $(47.7 \pm 6.8)$ application frequencies $(p=0.149)$, and also after 6 months there was insignificant difference between once daily (48.8 \pm 7.3$)$ and twice daily $(45.8 \pm 5.6)$ application frequencies $(\mathrm{p}=0.183)$. In the test group (CHX+Propolis+Clove), once daily application frequency $(88.7 \pm 4.1)$ showed insignificant difference in risk values compared to twice daily application frequency (87.3 \pm 4.9$)$ at base line ( $p=0.334)$ but after 3 months, there was significantly higher risk values for once daily application frequency $(50.8 \pm 5.5)$ compared to twice daily application frequency (46.3

\begin{tabular}{|c|c|c|c|c|c|c|}
\hline \multirow{2}{*}{ Caries Risk Percentage } & \multicolumn{2}{c|}{ Once daily } & \multicolumn{2}{c|}{ Twice daily } & \multirow{2}{*}{ p-value } \\
\cline { 3 - 7 } & Mean & SD & Mean & SD & \\
\hline \multirow{2}{*}{ Control Group } & Baseline & 87.8 & 4.3 & 90.3 & 2.3 & 0.09 NS \\
\cline { 2 - 7 } & $3 \mathrm{~m}$ & 50.8 & 5.8 & 47.7 & 6.8 & $0.149 \mathrm{NS}$ \\
\cline { 2 - 7 } & $6 \mathrm{~m}$ & 48.8 & 7.3 & 45.8 & 5.6 & $0.183 \mathrm{NS}$ \\
\hline \multirow{2}{*}{ Test Group } & Baseline & 88.7 & 4.1 & 87.3 & 4.9 & $0.334 \mathrm{NS}$ \\
\cline { 2 - 7 } & $3 \mathrm{~m}$ & 50.8 & 5.5 & 46.3 & 6.0 & $0.037^{*}$ \\
\cline { 2 - 7 } & $6 \mathrm{~m}$ & 49.7 & 6.7 & 46.3 & 6.0 & $0.136 \mathrm{NS}$ \\
\hline
\end{tabular}

Table 3: Mean and standard deviation (SD) for Caries Risk Percentage for different tested mouthwashes application frequency.

*: Significant; NS: Non-significant. 
Using A Mouthwash Containing Propolis, Clove Oil and Chlorhexidine to Improve the Caries Risk of High-risk Patients: Randomized Clinical Trial

$\pm 6.0)(p=0.037)$, and then after 6 months there was insignificant difference between once daily $(49.7 \pm 6.7)$ and twice daily $(46.3 \pm$ 6.0) application frequencies $(\mathrm{p}=0.827)$.

Figure 2 is a bar chart that showed mean Caries Risk Percentage for different tested mouthwashes application frequencies where the control group showed insignificant difference between once daily and twice daily application frequencies at base line, after 3 months, and after 6 months. Also, in the test group; once daily application frequency showed insignificant difference in risk values compared to twice daily application frequency at base line but after 3 months, there was significantly higher risk values for the once daily application frequency group compared to twice daily application frequency group and then after 6 months there was insignificant difference between once daily and twice daily application frequencies.

\section{Comparison between different tested follow-up}

Table 4 revealed the mean and standard deviation for Caries Risk Percentage for different follow up intervals where the control group (CHX only) showed significant decrease after 3 months $(50.8 \pm 5.8)$ followed by further significant decrease after 6 months $(48.8 \pm 7.3)$ for the once daily application frequency. It showed the

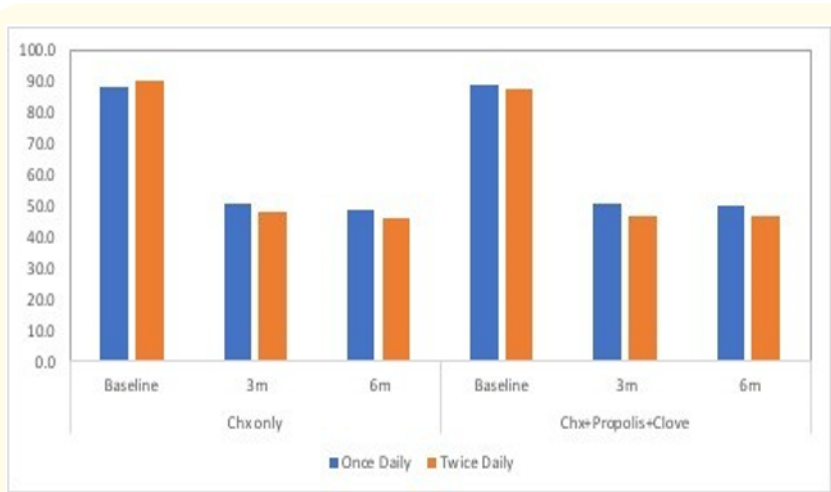

Figure 2: Bar chart for mean Caries Risk Percentage for different tested mouthwashes application frequency.

same for the twice daily application frequency where a significant decrease resulted after 3 months (50.8 \pm 5.8 ) followed by further significant decrease after 6 months $(45.8 \pm 5.6)$. On the other hand, in the test group ( $\mathrm{CHX}+$ Propolis+Clove), it showed that significant decrease resulted after 3 months (50.8 \pm 5.5$)$ followed by insignificant decrease after 6 months $(49.7 \pm 6.7)$ for the once daily application frequency and the same for the twice daily application frequency where significant decrease resulted after 3 months $(46.3 \pm$ 6.0) $(\mathrm{p}<0.001)$ followed by insignificant decrease after 6 months $(45.3 \pm 5.0)$.

\begin{tabular}{|c|c|c|c|c|c|c|c|c|}
\hline \multirow{2}{*}{\multicolumn{2}{|c|}{ Caries Risk Percentage }} & \multicolumn{2}{|c|}{ Baseline } & \multicolumn{2}{|c|}{$3 m$} & \multicolumn{2}{|c|}{$6 m$} & \multirow{3}{*}{$\begin{array}{c}\text { p-value } \\
<0.001^{*}\end{array}$} \\
\hline & & \multirow{2}{*}{$\begin{array}{l}\text { Mean } \\
87.8 \mathrm{a}\end{array}$} & \multirow{2}{*}{$\begin{array}{l}\text { SD } \\
4.3 \\
\end{array}$} & \multirow{2}{*}{$\begin{array}{l}\text { Mean } \\
50.8 \mathrm{~b}\end{array}$} & \multirow{2}{*}{\begin{tabular}{|l|} 
SD \\
5.8 \\
\end{tabular}} & \multirow{2}{*}{$\begin{array}{l}\text { Mean } \\
48.8 \mathrm{c}\end{array}$} & \multirow{2}{*}{$\begin{array}{l}\text { SD } \\
7.3\end{array}$} & \\
\hline Control Group & Once Daily & & & & & & & \\
\hline & Twice Daily & $90.3 a$ & 2.3 & $47.7 \mathrm{~b}$ & 6.8 & $45.8 \mathrm{c}$ & 5.6 & $<0.001^{*}$ \\
\hline \multirow[t]{2}{*}{ Test Group } & Once Daily & $88.7 \mathrm{a}$ & 4.1 & $50.8 \mathrm{~b}$ & 5.5 & $49.7 \mathrm{~b}$ & 6.7 & $<0.001^{*}$ \\
\hline & Twice Daily & $87.3 a$ & 4.9 & $46.3 \mathrm{~b}$ & 6.0 & $45.3 \mathrm{~b}$ & 5.0 & $<0.001^{*}$ \\
\hline
\end{tabular}

Table 4: Mean and standard deviation (SD) for Caries Risk Percentage for different follow- up intervals.

Different letter within each row indicates a significant difference. *: Significant; NS: Non-significant.

Figure 3 is a line chart showing the mean Risk Percentage for different tested follow-up intervals where the control group showed significant decrease after 3 months followed by further significant decrease after 6 months for the once daily application frequency. It showed the same for the twice daily application frequency where a significant decrease resulted after 3 months followed by further significant decrease after 6 months. On the other hand, in the test group, it showed that significant decrease resulted after 3 months followed by insignificant decrease after 6 months for the once daily application frequency and the same for the twice daily application frequency where significant decrease resulted after 3 months followed by insignificant decrease after 6 months. 




Figure 3: Line chart for mean Caries Risk Percentage for different tested follow-up intervals.
Colony forming units $/ \mathrm{ml}$

For each participant in this study bacterial count for $S$. mutans was performed at the three different time intervals by incubating saliva samples on mitis salivarius bacitracin agar after three tenfold dilutions were performed for each sample. Bacterial counts were expressed as Colony Forming Units (CFU)/ml x104.

\section{Comparison between different tested mouthwashes}

Table 5 presents mean and standard deviation for $\mathrm{CFU} / \mathrm{ml}$ x104 for different tested groups where the once daily application frequency had insignificant difference between control (CHX only) (360.8 \pm 32.2$)$ and test (CHX+Propolis+Clove) $(359.8 \pm 35.0)$ groups at base line $(\mathrm{p}=0.929)$. Also, after 3 months it showed

\begin{tabular}{|l|c|c|c|c|c|c|}
\hline \multirow{2}{*}{ CFU/ml x104 } & \multicolumn{2}{c|}{ Control } & \multicolumn{2}{c|}{ Test } & \multirow{2}{*}{ p-value } \\
\cline { 2 - 6 } & & Mean & SD & Mean & SD & \\
\hline \multirow{2}{*}{ Once Daily } & Baseline & 360.8 & 32.2 & 359.8 & 35.0 & 0.929 NS \\
\cline { 2 - 7 } & $3 \mathrm{~m}$ & 291.3 & 51.7 & 276.6 & 50.7 & $0.348 \mathrm{NS}$ \\
\cline { 2 - 7 } & $6 \mathrm{~m}$ & 272.3 & 63.4 & 255.8 & 54.8 & $0.345 \mathrm{NS}$ \\
\hline \multirow{2}{*}{ Twice Daily } & Baseline & 372.9 & 25.6 & 361.8 & 32.6 & $0.320 \mathrm{NS}$ \\
\cline { 2 - 7 } & $3 \mathrm{~m}$ & 211.6 & 38.6 & 188.3 & 30.5 & $0.137 \mathrm{NS}$ \\
\cline { 2 - 7 } & $6 \mathrm{~m}$ & 184.4 & 40.4 & 171.4 & 31.3 & $0.457 \mathrm{NS}$ \\
\hline
\end{tabular}

Table 5: Mean and standard deviation (SD) for CFU/ml x104 for different tested groups.

*: Significant; NS: Non-significant.

insignificant difference between control $(291.3 \pm 51.7)$ and test (276.6 \pm 50.7$)$ groups $(\mathrm{p}=0.348)$, and after 6 months, insignificant difference between control (272.3 \pm 63.4$)$ and test $(255.8 \pm 54.8)$ groups at $\mathrm{p}=0.345$. For the twice daily application frequency the control group (372.9 \pm 25.6$)$ had insignificant difference in CFU/ $\mathrm{ml}$ counts compared to test group $(361.8 \pm 32.6)$ at base line $(\mathrm{p}$ $=0.320$ ). Again after 3 months it showed insignificant difference between control $(211.6 \pm 38.6)$ and test $(188.3 \pm 30.5)$ groups at $p=0.137$. Then after 6 months, it showed insignificant difference between control $(184.4 \pm 40.4)$ and test $(171.4 \pm 31.3)$ groups $(p$ $=0.457)$.

Figure 4 is a bar chart showing mean $\mathrm{CFU} / \mathrm{ml}$ x104 for different tested mouthwashes where the once daily application frequency had insignificant difference between control and test groups at base line, after 3 months, and after 6 months. For the twice daily application frequency it showed that the control group had insignificant difference in $\mathrm{CFU} / \mathrm{ml}$ counts compared to test group at base line, after 3 months, and after 6 months. 


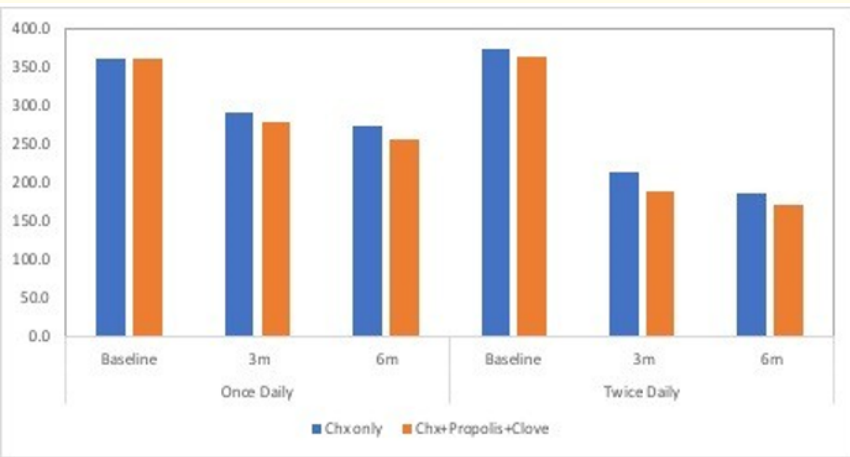

Figure 4: Bar chart for mean CFU/ml x104 for different tested mouthwashes.
Comparison between different tested mouthwashes application frequencies

Table 6 revealed the mean and standard deviation for CFU/ $\mathrm{ml}$ x104 for different tested mouthwashes application frequencies where the control group (CHX only) had insignificant difference between once daily (360.8 \pm 32.2$)$ and twice daily (372.9 \pm $25.6)$ application frequencies at base line $(p=0.281)$. On the other hand, after 3 months it showed significant difference in the mean $\mathrm{CFU} / \mathrm{ml}$ between once daily $(291.3 \pm 51.7)$ and twice daily groups $(211.6 \pm 38.6)(\mathrm{p}<0.001)$. It showed the same after 6 months, significant difference in the $\mathrm{CFU} / \mathrm{ml}$ between once daily $(272.3 \pm 63.4)$ and twice daily groups $(184.4 \pm 40.4)(\mathrm{p}<0.001)$. In the test group

\begin{tabular}{|c|c|c|c|c|c|c|}
\hline \multirow{2}{*}{ CFU/ml x104 } & \multicolumn{2}{c|}{ Once Daily } & \multicolumn{2}{c|}{ Twice Daily } & \multirow{2}{*}{ p-value } \\
\cline { 3 - 7 } & & Mean & SD & Mean & SD & \\
\hline \multirow{2}{*}{ Control Group } & Baseline & 360.8 & 32.2 & 372.9 & 25.6 & $0.281 \mathrm{NS}$ \\
\cline { 2 - 7 } & $3 \mathrm{~m}$ & 291.3 & 51.7 & 211.6 & 38.6 & $<0.001^{*}$ \\
\cline { 2 - 7 } & $6 \mathrm{~m}$ & 272.3 & 63.4 & 184.4 & 40.4 & $<0.001^{*}$ \\
\hline \multirow{2}{*}{ Test Group } & Baseline & 359.8 & 35.0 & 361.8 & 32.6 & $0.863 \mathrm{NS}$ \\
\cline { 2 - 7 } & $3 \mathrm{~m}$ & 276.6 & 50.7 & 188.3 & 30.5 & $<0.001^{*}$ \\
\cline { 2 - 7 } & $6 \mathrm{~m}$ & 255.8 & 54.8 & 171.4 & 31.3 & $<0.001^{*}$ \\
\hline
\end{tabular}

Table 6: Mean and standard deviation (SD) for CFU/ml x104 for different tested mouthwashes application frequency.

*: Significant; NS: Non-significant.

(CHX+Propolis+Clove) it showed insignificant difference between once daily (359.8 \pm 35.0$)$ and twice daily (361.8 \pm 32.6$)$ application frequencies at base line $(p=0.863)$ and as for the control group it showed significant difference in the $\mathrm{CFU} / \mathrm{ml}$ between once daily $(276.6 \pm 50.7)$ and twice daily $(188.3 \pm 30.5)$ application frequencies after 3 months $(\mathrm{p}<0.001)$. It showed the same after 6 months that there was significant difference in the $\mathrm{CFU} / \mathrm{ml}$ between once daily (255.8 \pm 54.8$)$ and twice daily $(171.4 \pm 31.3)$ application frequencies $(\mathrm{p}<0.001)$.

Figure 5 is a bar chart showing mean CFU/ml x104 for different tested mouthwashes application frequencies where the control group had insignificant difference between once daily and twice

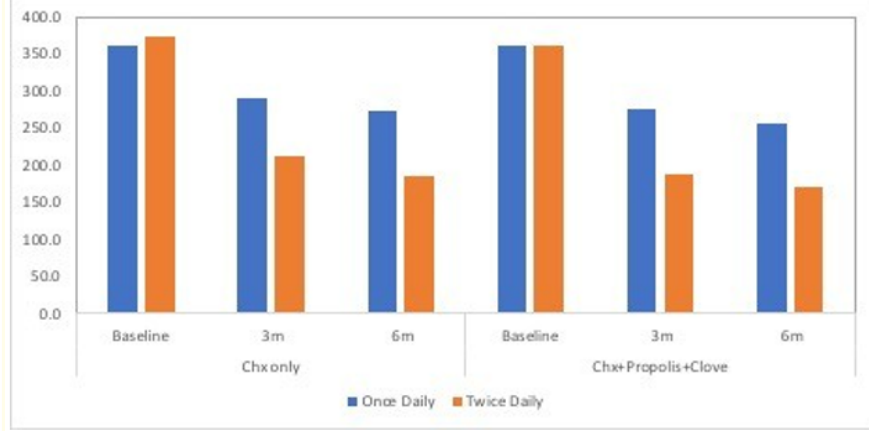

Figure 5: Bar chart for mean CFU/ml x104 for different tested mouthwashes application frequencies. 
Using A Mouthwash Containing Propolis, Clove Oil and Chlorhexidine to Improve the Caries Risk of High-risk Patients: Randomized Clinical Trial

daily application frequencies at base line. On the other hand, after 3 months it showed significant difference in the mean $\mathrm{CFU} / \mathrm{ml}$ between once daily and twice daily groups. It showed the same after 6 months, significant difference in the $\mathrm{CFU} / \mathrm{ml}$ between once daily and twice daily groups. In the test group it showed insignificant difference between once daily and twice daily application frequencies at base line and as for the control group it showed significant decrease in the $\mathrm{CFU} / \mathrm{ml}$ between once daily and twice daily application frequencies after 3 months. It showed the same after 6 months that there was significant difference in the $\mathrm{CFU} / \mathrm{ml}$ between once daily and twice daily application frequencies.
Comparison between different tested follow-up intervals

Table 7 presents mean and standard deviation for CFU/ml x104 for different follow-up intervals where the control group (CHX only) had a baseline $(360.8 \pm 32.2)$ then a significant decrease after 3 months $(291.3 \pm 51.7)$ followed by further significant decrease after 6 months $(272.3 \pm 63.4)$ for the once daily application frequency. It showed the same for the twice daily application frequency group which had a baseline $(372.9 \pm 25.6)$ then a significant decrease after 3 months $(211.6 \pm 38.6)$ followed by further significant decrease after 6 months $(184.4 \pm 40.4)$. Equally, in the test group $(\mathrm{CHX}+$ Propolis+Clove) the baseline $\mathrm{CFU} / \mathrm{ml}$ count was $(359.8 \pm$

\begin{tabular}{|c|c|c|c|c|c|c|c|c|}
\hline \multirow{2}{*}{\multicolumn{2}{|c|}{$\mathrm{CFU} / \mathrm{ml} \times 104$}} & \multicolumn{2}{|c|}{ Baseline } & \multicolumn{2}{|c|}{$3 \mathrm{~m}$} & \multicolumn{2}{|c|}{$6 \mathrm{~m}$} & \multirow{3}{*}{$\begin{array}{l}\text { p-value } \\
<0.001^{*}\end{array}$} \\
\hline & & \multirow{2}{*}{$\begin{array}{c}\text { Mean } \\
360.8 \mathrm{a} \\
\end{array}$} & \multirow{2}{*}{\begin{tabular}{|c|} 
SD \\
32.2 \\
\end{tabular}} & \multirow{2}{*}{\begin{tabular}{|c|} 
Mean \\
$291.3 b$ \\
\end{tabular}} & \multirow{2}{*}{\begin{tabular}{|c|} 
SD \\
51.7 \\
\end{tabular}} & \multirow{2}{*}{\begin{tabular}{|l} 
Mean \\
$272.3 \mathrm{c}$ \\
\end{tabular}} & \multirow{2}{*}{\begin{tabular}{|c|} 
SD \\
63.4 \\
\end{tabular}} & \\
\hline Control Group & Once Daily & & & & & & & \\
\hline & Twice Daily & $372.9 a$ & 25.6 & $211.6 b$ & 38.6 & $184.4 \mathrm{c}$ & 40.4 & $<0.001^{*}$ \\
\hline \multirow[t]{2}{*}{ Test Group } & Once Daily & $359.8 a$ & 35.0 & $276.6 b$ & 50.7 & $255.8 \mathrm{c}$ & 54.8 & $<0.001^{*}$ \\
\hline & Twice Daily & $361.8 \mathrm{a}$ & 32.6 & $188.3 b$ & 30.5 & $171.4 \mathrm{c}$ & 31.3 & $<0.001^{*}$ \\
\hline
\end{tabular}

Table 7: Mean and standard deviation (SD) for CFU/ml x104 for different follow-up intervals.

Different letter within each row indicates a significant difference. *: Significant; NS: Non-significant.

35) followed by significant decrease after 3 months (276.6 \pm 50.7$)$ then further significant decrease after 6 months $(255.8 \pm 54.8)$ for the once daily application frequency. The same resulted for the twice daily application frequency where the baseline was (361.8 \pm 32.6) and then significant decrease resulted after 3 months (188.3 \pm 30.5 ) followed by further significant decrease after 6 months $(171.4 \pm 31.3)$.

Figure 6 is a line chart for mean CFU/ml x104 for different tested follow-up intervals where the control group had a significant decrease after 3 months followed by further significant decrease after 6 months for the once daily application frequency. It showed the same for the twice daily application frequency group which

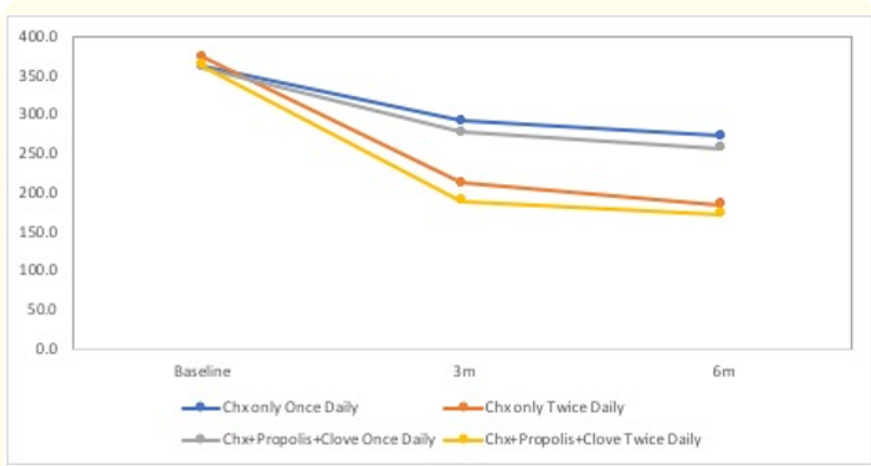

Figure 6: Line chart for mean CFU/ml x104 for different tested follow-up intervals. had a significant decrease after 3 months followed by further sig- 
nificant decrease after 6 months. Equally, in the test group there was s significant decrease after 3 months then further significant decrease after 6 months for the once daily application frequency. The same resulted for the twice daily application frequency where a significant decrease resulted after 3 months followed by further significant decrease after 6 months.

\section{Discussion}

Dental caries is the most common and costly chronic disease of the dental hard tissues. It arises from the interactions between the oral inhabitant cariogenic bacteria, the teeth, diet content and frequency and saliva. S. mutans is regarded as one of the main microorganisms participating in the formation of dental caries. Their level reduction in the oral cavity will definitely reduce the prevalence of dental caries. The absolute removal of $S$. mutans from the oral cavity is clinically impossible, but their numbers could be dramatically reduced so it becomes less virulent with the aid of different preventive measures such as teeth brushing using fluoride dentifrices and the use of an antimicrobial mouthwash and so this study was conducted to determine the effect of using mouthwash of propolis, clove oil and chlorhexidine versus chlorhexidine mouthwash on the risk assessment of patients with high caries risk. The study was a randomized prospective clinical trial [26-28].

It is proven that cariogenic microorganisms, especially $S . m u-$ tans play an essential role in the pathogenesis of dental caries. It is involved in the initiation of almost all carious lesions in enamel [29]. The main cause of dental caries was attributed to oral biofilm, also known as dental plaque, a film of microorganisms sticking to the tooth surface [30]. Dental biofilms constitute an ecosystem of bacteria. They produce acids from carbohydrate metabolism, subsequently a decrease in environmental $\mathrm{pH}$ causes the demineralization of tooth surface and therefore the development of dental caries. The development of dental caries involves acidogenic and aciduric Gram-positive bacteria ( $S$. mutans, Lactobacilli and Actinomycetes). However, much research has identified $S$. mutans as the major pathogens of dental caries. This is because $S$. mutans are frequently isolated from cavitated caries lesions, it induces caries formation in animals which are fed with a sucrose-rich diet and it is highly acidogenic and aciduric [31]. So, it is logical that the decrease of $S$. mutans counts in the oral environment would decrease the risk of developing new caries lesions.
During the selection of participants, any patient with history of taking antibiotics, mouthwash, history of professionally applied topical fluoride 3 months prior to the course of the study, or patients using removable dental prosthetic was excluded to avoid any positive or negative effect as possible of any material on the oral $S$. mutans count [14].

According to a study conducted by Petersson., et al. (2002) [17] the Cariogram predicted caries increment more accurately than any other single-factor model. They also stated that it serves as a useful visual aid for clinicians when talking to patients about caries danger.

These findings were supported later on by Gao., et al. (2013) [32] in a study conducted to assess the validity of different caries risk assessment programmes in preschool children that included two types of risk assessment tools, namely reasoning-based caries risk assessment models that consisted of the Caries Risk Assessment Tool (CAT) and Caries Management by Risk Assessment (CAMBRA) programme, and algorithm-driven programmes consisting the Cariogram and National University of Singapore Caries Risk Assessment (NUS-CRA) models. In the former, important risk factors and indicators were synthesized into a checklist and one's risk to disease is qualitatively estimated, whereas in the latter, one's risk was quantitatively calculated through algorithms. The CAT and CAMBRA had an extremely high sensitivity but low specificity; almost all children with new caries were defined as high risk, but many children without new caries were also defined as high risk (i.e. a high false positive rate). Such overestimation may have originated from some of the classification criteria, of which some single indicators alone were sufficient to justify a high-risk diagnosis. The overestimation of risk leads to overtreatment and a waste of resources. This study supported a superior validity of algorithm-driven programmes contributed to their higher (Sensitivity + Specificity) of Cariogram and NUS-CRA, compared with CAT and CAMBRA. While a reasoning-based checklist generates a rough estimate of one's risk to disease, algorithms quantitatively synthesize risk factors and indicators, define their weights, and are therefore more likely to provide refined risk calculation. Algorithm driven approach was also successfully used in the medical field for predicting chronic diseases, such as cardiovascular disease (e.g. 
Framingham risk equation, QRISK, and ASSIGN) [33]. The Cariogram was reported to have a high performance in adolescents and elders but a relatively low performance in children. It may be reasonable to incorporate some age-specific factors (e.g. milk bottle use) into Cariogram and recalibrate the built-in algorithms for young children [34].

The results of this study showed that the mean caries risk percentage for the once daily application group had no significant difference between the control (CHX only) (87.8 \pm 4.3 ) and test $(\mathrm{CHX}+$ Propolis+Clove $)(88.7 \pm 4.1)$ groups at base line, after 3 months (50.8 \pm 5.8$)(50.8 \pm 5.5)$ and after 6 months $(48.8 \pm 7.3)$ $(49.7 \pm 6.7)$ respectively. As for the twice daily application group; control group $(90.3 \pm 2.3)$ showed marginally higher risk values compared to test group $(87.3 \pm 4.9)$ at baseline but after 3 months $(47.7 \pm 6.8)(46.3 \pm 6.0)$ and 6 months $(45.8 \pm 5.6)(46.3 \pm 6.0)$ respectively the differences were insignificant. These findings suggest that adding propolis and clove oil to Chlorhexidine did not significantly improve the risk assessment of the participants. This is further proven by the bacterial count analysis which showed insignificant difference in $S$. mutans counts between control and test groups for the once and twice application frequencies of the mouthwash although the test group $(255.8 \pm 54.8)(171.4 \pm 31.3)$ showed higher reduction in $S$. mutans counts than the control group $(272.3 \pm 63.4)(184.4 \pm 40.4)$ at the end of this study. These findings agrees with the study conducted by Hegde., et al. (2013) [10] who studied the effect of propolis on S. mutans counts in vivo and found that propolis extract possessed anti-microbial effect on S. mutans and can be used as a prevention measure of dental caries.

However, this comes in disagreement with the study conducted by Akca., et al. (2016) [35] who evaluated the antimicrobial effect of ethanolic extract of propolis (EEP) in comparison to chlorhexidine gluconate (CHX) on oral pathogens in vitro and their results showed that the MIC ${ }^{1}$ and $\mathrm{MBC}^{2}$ for both EEP and CHX on the S. $m u$ tans where similar. This may be due to the different study design as they tested both solutions on the bacterial biofilm in vitro and they tested the EEP alone without any addition of CHX or clove oil like our study. Also Marya., et al. (2015) [36] findings disagree with our study as their study compared the antimicrobial efficacy of brazillian propolis with Chlorhexidine and Sodium Fluoride against common oral pathogens (S. mutans, Candida Albicans and Escherichia Coli) in vitro. Their results were that both Chlorhexidine and propolis showed an antimicrobial activity against all tested pathogens and Chlorhexidine had the highest efficacy against $S$. mutans and E. coli but C. Albicans was more sensitive to propolis. The sodium fluoride group had no antimicrobial effect against the three tested pathogens. This disagreement may be attributed to the different study design as they tested their mouthwashes against freeze dried cultures of the pathogens and determined the antimicrobial activity by measuring the zone of inhibition that resulted. They also used a mouth rinse containing an extract of propolis only not a combination of propolis and Chlorhexidine. The studies that discussed the effect of Chlorhexidine on caries risk assessment are numerous but none compared its effect to a combination with other antimicrobials like our study.

As for the application frequency the results showed that there were no significant differences within the control or test groups in the caries risk percentage. However, the bacterial count analysis showed statistical significance at 3 months and 6 months in favor of the twice daily application frequency. This is in accordance with Lang and Grossman (1981) [37] and Clavero., et al. (2003) [38] who concluded that the antimicrobial effect of Chlorhexidine lasted for 12 hours and thus Chlorhexidine should be prescribed twice daily to be effective in the retardation and reduction of the S. mutans counts.

Despite the significant reduction in $S$. mutans counts in both control and test groups, the caries risk assessment was insignificantly affected. This may be attributed to the fact that there are 10 different parameters affecting the Cariogram's risk assessment, each parameter has a specific weight in the final pie chart presentation and the differences in bacterial counts did not significantly affect the scores of $S$. mutans count and consequentially the caries risk assessment.

When the caries risk percentage of the control group was analyzed, there was a significant decrease after 3 months and further

${ }^{1}$ Minimum Inhibitory Concentration

${ }^{2}$ Minimum Bactericidal Concentration

Citation: Moataz Gamal Konsouh., et al. "Using A Mouthwash Containing Propolis, Clove Oil and Chlorhexidine to Improve the Caries Risk of High-risk Patients: Randomized Clinical Trial”. Acta Scientific Dental Sciences 5.1 (2021): 77-92. 
significant decrease after 6 months for both application frequencies. Also, in the test group there was significant decrease of the caries risk among the participants after 3 and 6 months. Although there was significant reduction in the $S$. mutans counts for all groups, this acute drop in caries risk cannot be attributed to the reduction in bacterial counts alone as there was also the improvement of the fluoride program for all participants and the improvement in diet contents and frequencies for some of them which may have greatly contributed to the reduced caries risk outcome for the participants in this study.

A study was conducted by combining the evaluation of the activity of preventive methods and the Cariogram program by Mannaa., et al. (2014) [39] who evaluated the effectiveness of using 5000 ppm fluoride toothpaste using Cariogram for six weeks. They stated in their study that there was a significant decrease in all of the participants caries risk after six weeks which is consistent with our study findings.

In a study conducted by Karabekiroğlu and Ünlü (2017) [40] on the effectiveness of different preventive programs in Cariogram parameters of young adults at high caries risk for the period of three months, they found that all preventive programs (fluoridated tooth paste, one visit application of Fluoride varnish and Chlorhexidine varnishes) tested had significantly reduced the caries risk of the participants according to the Cariogram which comes in agreement with our study.

Based on the resulted outcomes of this study, the null hypothesis tested that there is no difference between the effect of using a mouthwash that contains a mix of propolis, clove oil, and chlorhexidine and a mouthwash containing chlorhexidine alone on the patient's caries risk assessment was accepted.

\section{Conclusion}

Within the limitations of this study, it can be concluded that:

- Adding propolis and clove oil to Chlorhexidine is not beneficial in caries prevention.

- The addition of propolis and clove oil to Chlorhexidine did not affect the reduction of bacterial $S$. mutans count in the oral cavity to a clinical significance.
- Adding propolis and clove oil did not prolong the antimicrobial effect of Chlorhexidine on S. mutans.

- Chlorhexidine mouthwash should be used twice daily to have a substantial effect in reducing oral $S$. mutans count.

\section{Acknowledgements}

Special thanks to the head, members and supporting staff of the Conservative Dentistry department of the Faculty of Dentistry - Cairo University for their help and support throughout this research.

\section{Conflict of Interest}

No conflict of interest or financial issues to report in this research.

\section{Bibliography}

1. Kim MJ., et al. "Antimicrobial effect of Korean propolis against the mutans streptococci isolated from Korean". Journal of Microbiology 49.1 (2011): 161-164.

2. Duailibe SADC., et al. "Effect of a propolis extract on Streptococcus mutans counts in vivo". Journal of Applied Oral Science 15.5 (2007): 420-423.

3. Fure S. "Ten-Year Incidence of Tooth Loss and Dental Caries in Elderly Swedish Individuals". Caries Research 37.6 (2003): 462-469.

4. Petersen PE and Yamamoto T. "Improving the oral health of older people: The approach of the WHO Global Oral Health Programme". Community Dentistry and Oral Epidemiology 33.2 (2005): 81-92.

5. Suneja ES., et al. "An Overview of Caries Risk Assessment: Rationale, Risk Indicators, Risk Assessment Methods, and Risk-based Caries Management Protocols". Indian Journal of Dental Sciences 9.3 (2017): 210-214.

6. Autio-Gold J. "The Role of Chlorhexidine in Caries Prevention". Operative Dentistry 33 (2008): 710-716. 
7. Walsh T., et al. "Chlorhexidine treatment for the prevention of dental caries in children and adolescents". Cochrane Database System Review 2015.4 (2015).

8. Marcucci MC. "Propolis: chemical composition, biological properties and therapeutic activity". Apidologie 26.2 (1995): 83-99.

9. Özan F., et al. "Effect of Mouthrinse Containing Propolis on Oral Microorganisms and Human Gingival Fibroblasts". European Journal of Dentistry 01.4 (2007): 195-201.

10. Hegde KS., et al. "Effect of Propolis on Streptococcus mutans Counts: An in Vivo Study". International Journal of Clinical Pediatric Dentistry 6.1 (2013): 22-25.

11. Nzeako BC., et al. "Antimicrobial activities of clove and thyme extracts". Sultan Qaboos University Medical Journal 6.1 (2006): 33-39.

12. Sabiha Shaheen S., et al. "Antimicrobial efficacy of ten commercially available herbal dentifrices against specific oral microflora - in vitro study". Journal of Clinical and Diagnostic Research 9.4 (2015): 42-46.

13. Kanth MR., et al. "Efficacy of specific plant products on dental caries causing microorganisms". Journal of Clinical and Diagnostic Research 10.12 (2016): ZM01-3.

14. Featherstone JDB., et al. "A randomized clinical trial of anticaries therapies targeted according to risk assessment (caries management by risk assessment)". Caries Research 46.2 (2012): 118-129.

15. Sen N., et al. "A comparative assessment of caries risk using cariogram among smokers and smokeless tobacco users in india - a cross-sectional study". African Health Science 18.4 (2018): 1046-1056.

16. Netto CA., et al. "Effects of typified propolis on mutans streptococci and lactobacilli: a randomized clinical trial”. Brazilian Dental Science 16.2 (2013): 31-36.
17. Petersson HG., et al. "Evaluation of a computer program for caries risk assessment in schoolchildren”. Caries Research 36.5 (2002): 327-340.

18. Anna Y Alian., et al. "Assessment of Caries Risk in Elderly Patients Using the Cariogram Model". Journal of the Canadian Dental Association (Tor). 72.5 (2006): 459-463.

19. Rosenow EC. "Studies on Elective Localization Focal Infection with Special Reference to Oral Sepsis". Journal of Dental Research 1.3 (1919): 205-267.

20. Da Silva ACB., et al. "Detection of oral streptococci in dental biofilm from caries-active and caries-free children”. Brazilian Journal of Microbiology 39.4 (2008): 648-651.

21. Hsu KLC., et al. "Variability of two plaque sampling methods in quantitation of streptococcus mutans". Caries Research 44.2 (2010): 160-164.

22. Subramaniam P., et al. "Effect of pomegranate and aloe vera extract on streptococcus mutans: An in vitro study". Dental Hypotheses 3.3 (2012): 99-105.

23. Maldupa I., et al. "Comparative analysis of CRT Buffer, GC saliva check buffer tests and laboratory titration to evaluate saliva buffering capacity". Stomatologija. Baltic Dental and Maxillofacial Journal 13.2 (2011): 55-61.

24. Silness J and LöE H. "Periodontal disease in pregnancy. II. Correlation between oral hygiene and periodontal conditions". Acta Odontologica Scandinavica 22 (1964): 121-135.

25. Bardisi W., et al. "Cariogram and Caries Risk Assessment for Athletes”. Egyptian Dental Journal 64.3 (2018): 1181-1187.

26. Kulkarni V V and Damle SG. "Comparative evaluation of efficacy of sodium fluoride, chlorhexidine and triclosan mouth rinses in reducing the mutans streptococci count in saliva: an in vivo study". Journal of Indian Society of Pedodontics and Preventive Dentistry 21.3 (2003): 98-104. 
27. Jeon JG., et al. "Natural products in caries research: Current (limited) knowledge, challenges and future perspective". Caries Research 45.3 (2011): 243-263.

28. Ohta M., et al. "Evaluation of the Proportion of Cariogenic Bacteria Associated with Dental Caries". Epidemiology 07.5 (2017): 1-6.

29. Samaranayake L. "Essential Microbiology for Dentistry". 4th Editio. New York: Churchil Livingstone (2011): 121-193.

30. Marsh PD. "Microbiological Aspects of the Chemical Control of Plaque and Gingivitis". Journal of Dental Research 71.7 (1992): 1431-1438.

31. Takahashi N and Nyvad B. "The role of bacteria in the caries process: Ecological perspectives". Journal of Dental Research 90.3 (2011): 294-303.

32. Gao X., et al. "Validity of caries risk assessment programmes in preschool children". Journal of Dentistry 41.9 (2013): 787-795.

33. Dent THS. "Predicting the risk of coronary heart disease. I. The use of conventional risk markers". Atherosclerosis 213.2 (2010): 345-351.

34. Gao X., et al. "Caries risk assessment programmes for Hong Kong children”. Hong Kong Medical Journal 21.6 (2015): S4246.

35. Akca AE., et al. "The Comparative Evaluation of the Antimicrobial Effect of Propolis with Chlorhexidine against Oral Pathogens: An in Vitro Study". Biomed Research International 2016 (2016).

36. Marya CM., et al. "Comparison of antimicrobial efficacy of brazilian propolis with chlorhexidine and sodium fluoride against common oral pathogens: An In Vitro study". Jundishapur Journal of Natural Pharmaceutical Products 10.2 (2015): 1-6.

37. Lang NP and Grossman KR. "Optimal dosage of chlorhexidine digluconate in chemical plaque control when applied by the oral irrigator". Journal of Clinical Periodontology 8 (1981): 189-202.
38. Clavero J., et al. "Effects of $0.2 \%$ chlorhexidine spray applied once or twice daily on plaque accumulation and gingival inflammation in a geriatric population". Journal of Clinical Periodontology 30.9 (2003): 773-777.

39. Mannaa A., et al. "Caries-risk profile variations after shortterm use of 5000 ppm fluoride toothpaste". Acta Odontologica Scandinavica 72.3 (2014): 228-234.

40. Karabekiroğlu S and Ünlü N. "Effectiveness of Different Preventive Programs in Cariogram Parameters of Young Adults at High Caries Risk". Hindawi International Journal of Dentistry 2017.7189270 (2017): 1-10.

\section{Assets from publication with us}

- Prompt Acknowledgement after receiving the article

- Thorough Double blinded peer review

- Rapid Publication

- Issue of Publication Certificate

- High visibility of your Published work

Website: www.actascientific.com/

Submit Article: www.actascientific.com/submission.php Email us: editor@actascientific.com

Contact uS: +919182824667 